\title{
Anti-small cell lung cancer and collagenase inhibition properties of hydroxysafflor yellow $A$
}

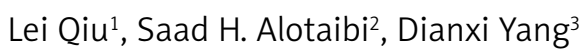

${ }^{1}$ Department of Respiratory and Critical Care Medicine, Shanxi Provincial People's Hospital, Taiyuan City, Shanxi, China

${ }^{2}$ Department of Chemistry, Turabah University College, Taif University, Taif,

Saudi Arabia

${ }^{3}$ Department of Thoracic Surgery, Sunshine Union Hospital, Weifang City, Shandong

Province, China

Submitted: 17 May 2021; accepted: 10 July 2021

Online publication: 9 July 2021

Arch Med Sci

DOI: https://doi.org/10.5114/aoms/138833

Copyright $\odot 2021$ Termedia \& Banach

\section{Abstract}

Introduction: Hydroxysafflor yellow A is the major active chemical ingredient of Carthamus tinctorius L. (safflower), which is widely used in patients with cardiovascular and cerebrovascular diseases in China.

Material and methods: In our study, the inhibitory effect of hydroxysafflor yellow $A$ on collagenase showed a lower value, $I_{50}=78.81 \mu \mathrm{g} / \mathrm{ml}$. In the cellular and molecular part of the recent study, the cells treated with hydroxysafflor yellow A were assessed by MTT assay for $48 \mathrm{~h}$ as regards the cytotoxicity and anti-small cell lung cancer effects on SBC-3, DMS273, and DMS114 cell lines.

Results: The viability of small cell lung cancer cell lines decreased dose-dependently in the presence of hydroxysafflor yellow $A$. The $\mathrm{IC}_{50}$ values of hydroxysafflor yellow A were 539, 432, and $416 \mu \mathrm{g} / \mathrm{ml}$ against SBC-3, DMS273, and DMS114 cell lines, respectively. A molecular docking study was carried out for evaluation of the biological activity of hydroxysafflor yellow A against the collagenase $\mathrm{H}$ from Clostridium histolyticum.

Conclusions: The results of the docking calculations revealed the considerable binding affinity of the inhibitor to the enzyme with a docking score of $-9.238(\mathrm{kcal} / \mathrm{mol})$. This remarkable binding affinity could be attributed to the number of hydrogen bonds and hydrophobic contacts, which are 6 and 10 , respectively.

Key words: hydroxysafflor yellow A, collagenase, molecular docking, antismall cell lung cancer.

\section{Introduction}

The flower of the safflower plant, Carthamus tinctorius L., has been used extensively in traditional Chinese medicine for treatment of cerebrovascular and cardiovascular diseases. The extracts from $C$. tinctorius contain yellow and red pigments including hydroxysafflor yellow $A$, safflomin A, safflomin C, safflor yellow B, as well as other chemicals. Hydroxysafflor yellow $A$, the main chemical component of the safflower yellow pigments, has been demonstrated to antagonize platelet activating factor receptor binding [1, 2]. Hypotensive, antithrombotic and inhibitory effects on platelet aggregation have been also reported. Many studies have demonstrated that safflower yellow possesses various physiologi-

\author{
Corresponding author: \\ Dianxi Yang \\ Department \\ of Thoracic Surgery \\ Sunshine Union Hospital \\ Weifang City \\ Shandong Province \\ 261000, China \\ E-mail: \\ huiluotianshi1207@sina.com, \\ erbahrami@yahoo.com
}


cal and pharmacological activities, including antithrombotic and anti-hypertensive activities [3]. Hydroxysafflor yellow A, which is the effective water-soluble monomer of safflower yellow, has been demonstrated to have anti-oxidative activities and myocardial and cerebral protective effects. More recent studies suggest that hydroxysafflor yellow A has therapeutic effects on Parkinson's disease $[4,5]$. Indeed, it was reported that hydroxysafflor yellow $A$ is able to inhibit endothelin release, increase myocardial flow, improve the metabolism of myocardial oxygen consumption, and inhibit myocardial ischemia. It was recorded that hydroxysafflor yellow A could reduce myocardial mitochondrial swelling, decrease mitochondrial membrane fluidity, and inhibit mitochondrial over-oxidation [6].

Collagenase (EC 3.4.24.3) enzyme is an enzyme belonging to the hydrolase class and breaks the 3-helix structure of collagen. Hydrolases mediate hydrolysis reactions, that is, the destruction of molecules with the help of $\mathrm{H}^{+}$and $\mathrm{OH}$ ions of water [7]. The enzyme named after its substrate is also known as matrix metallopeptidase-1 or matrix metalloprotease-1. Collagenases, depending on their type, have a weight range of 50$60 \mathrm{kDa}$. The cofactor is the metal $\mathrm{Zn}$. One group of proteases, which are extracellular proteolytic enzymes, are metalloproteases that require $\mathrm{Ca}^{2+}$ or $\mathrm{Zn}^{2+}$ ions in the bound state for their activation, while the other group is serine proteases containing reactive serine in their active site $[8,9]$. The breakdown of matrix proteins such as collagen, laminin and fibronectin by metalloproteases and serine proteases facilitates cell migration. Collagenase is one of these enzymes. These enzymes play an important role in physiological processes such as tissue restructuring, normal structuring of tissues and systems, wound healing and normal developmental processes, as well as in pathological processes such as the spread of tumor cells to surrounding tissues and disruption of their function $[10,11]$.

The theoretical investigation of experimental results is an essential work that has to be done as a complementary study. One of the most significant things about theoretical studies is that they can provide considerable insight into the experimental outcomes [12]. A popular method for such theoretical studies is molecular docking, which can contribute beneficial information about the interactions between various molecules and biological compounds. The prediction of mechanisms in which a molecule would inhibit the activity of an enzyme is predictable with molecular docking studies [13]. The binding affinity of the ligands to the biological materials is an essential outcome of molecular docking.
We also investigated hydroxysafflor yellow $A$ in cytotoxicity studies against common small cell lung cancer cell lines, i.e., SBC-3, DMS273, and DMS114, in vitro. Interestingly, we obtained significantly good results in the study. The best result was achieved in the case of the DMS114 cell line. Also, we investigated the enzyme inhibition and molecular docking studies in this study.

\section{Material and methods}

\section{Determination of cell toxicity and anticancer effects of hydroxysafflor yellow A}

MTT is a colorimetric technique. Based on the fact that living cells can carry out oxidative metabolism, as a result, oxidation breaks down the MTT dye and produces a dye ranging from yellow to blue. This test determines the number of living cells [14].

In this research, we used the following cell lines to evaluate anti-human small cell lung cancer and cytotoxici effects of hydroxysafflor yellow A using the MTT method:

- Small cell lung cancer cell lines: SBC-3, DMS273, and DMS114.

- Normal cell line: HUVEC.

For this purpose, each cell line was placed separately in T25 flasks with a complete culture medium (including DMEM (Dulbecco's Modified Eagle Medium), 10\% complementary bovine fetal serum, and $1 \%$ penicillin-streptomycin solution) and at $37^{\circ} \mathrm{C}$ in the incubator the cell culture was incubated with $5 \% \mathrm{CO}_{2}$. After obtaining $80 \%$ cell density, the sample was exposed to $1 \%$ trypsin-EDTA solution and after $3 \mathrm{~min}$ of incubation at $37^{\circ} \mathrm{C}$ in a cell culture incubator with $5 \% \mathrm{CO}_{2}$ and observation of cells removed from the bottom of the plate, the sample was centrifuged at $5000 \mathrm{rpm}$ for $5 \mathrm{~min}$ and then the cell precipitate was decrypted by adding trypsin culture medium. Then, the cell suspensions after adding trypan blue dye were counted by a neobar slide and a cytotoxicity test was performed by the MTT method [14].

Initially, 10,000 cells were implanted in cell culture plates and then the cells were treated at concentrations of $1-1000 \mu \mathrm{g} / \mathrm{ml}$ of tiliroside. After $24 \mathrm{~h}, 20 \mu \mathrm{l}$ of MTT dye was added to the wells and incubated for $5 \mathrm{~h}$ at $37^{\circ} \mathrm{C}$ with $5 \% \mathrm{CO}_{2}$. DMSO was then added to the wells to dissolve the formazan crystals and the absorption rate of the wells at 570 $\mathrm{nm}$ was read by an ELISA reader (ELISA Teknika Oraganon reader, Netherlands) and the cell viability rate was computed by the formula below [14]: Cell viability $(\%)=($ Sample $A /$ Control $A) \times 100$.

\section{Enzyme methods}

PHL83510-Hydroxysafflor yellow A (CAS Number 78281-02-4) was obtained from Sigma. The inhibitory effect on the collagenase enzyme as 
modified by Thring et al. (2009) [15] was determined spectrophotometrically. The solution of the compound and diluted solutions were prepared in our study. $50 \mu \mathrm{l}$ of the solution containing $0.8 \mathrm{U} / \mathrm{ml}$ collagenase was taken, and $50 \mu \mathrm{L}$ of the prepared chemical solution at different concentrations was added. Then $0.9 \mathrm{ml}$ of tricin buffer solution $\mathrm{pH} 7.5$ was added [16]. The plant extract and chemical substance solution were not put into the control solution. For the blank, DMSO solution was used in the same amount as the enzyme instead of the enzyme. The blank, control and sample solutions were left to the first incubation at $25^{\circ} \mathrm{C}$ for $30 \mathrm{~min}$ [17]. After this first incubation, $1 \mathrm{mM} 0.05 \mathrm{ml}$ of $\mathrm{N}$-(3-[2-furyl]acryloyl)-Leu-Gly-Pro-Ala (collagenase enzyme substrate) solution was added to all solutions and left for a second incubation for $15 \mathrm{~min}$ at $25^{\circ} \mathrm{C}$. Absorbance values against the blank at $340 \mathrm{~nm}$ were read in the UV spectrophotometer of the sample solutions and the control solution. The experiments were repeated twice. The inhibitory effect of the sample solutions at different concentrations prepared in the study on collagenase enzyme was calculated according to the following equation [18]: \% inhibition = $[(\Delta \mathrm{A} 340$ control $-\Delta \mathrm{A} 340$ sample $) / \Delta \mathrm{A} 340$ control $]$ $\times 100$, where $\Delta A 340$ control - absorbance value of the control solution, $\triangle \mathrm{A} 340$ sample - Absorbance value of the sample solution.

The $I C_{50}$ value, which is the amount of substance required for the collagenase enzyme to show a $50 \%$ inhibition effect, was calculated by the regression equation obtained from the linear part of the curve drawn by applying \% enzyme inhibition data to the abscess concentration in the graph [19].

\section{Molecular docking study}

The biological activities of various compounds can be easily investigated using theoretical approaches, and molecular docking studies are among the most popular methods for this purpose. The enzyme used in this study was collagenase $\mathrm{H}$ from Clostridium histolyticum (PDB ID: 4AR1) [20]. The biological activities of hydroxysafflor yellow $A$ were investigated against this enzyme. The structure of the enzyme was obtained from the Protein Data Bank (http://www.rcsb. org/pdb) and prepared with the protein preparation module of the Schrödinger Suite [21]. The hydrogen bond addition and removal of water molecules were carried out using this module. An $\mathrm{H}$-bond network was created using the optimization step. The structure was then minimized using the OPLS3e force field, and the prediction of active sites of the structure was performed utilizing SiteMap of Schrödinger [22]. The hydroxysafflor yellow A was obtained from the PubChem database in SDF format and prepared with the LigPrep module of Schrödinger [23]. Finally, the calculations of molecular docking were performed utilizing Glide of the Schrödinger Suite.

\section{Results and Discussion}

\section{Anticancer effect analysis}

One of the cytotoxicity test methods to measure the rate of cell death is the MTT method, which is based on the formation of formazan dye by reducing the substance MTT (dimethyl thiazole 2 and 5 diphenyltetrazolium bromide) or other tetrazolium salts [24, 25]. By breaking the MTT tetrazolium ring by mitochondrial enzymes in living cells, insoluble purple formazan crystals are formed. The formation of these crystals indicates the activity of respiratory chain enzymes and is a measure of cell viability. By measuring the amount of absorption with a spectrophotometer at specific wavelengths, the number of living cells can be determined. This test is performed according to ISO 10993-5 and its purpose is in vitro evaluation of cytotoxicity. The cytotoxicity test is performed according to ISO10993-5 standard and in four ways: the NRU test, the CFU test, the MTT test and the XTT test $[26,27]$. The most common method for assessing cytotoxicity is to measure cell survival by MTT. This method is based on the intensity of dye produced by the mitochondrial activity of cells, measured at a wavelength of 540 to $630 \mathrm{~nm}$ and directly proportional to the number of living cells. The increase or decrease in the number of living cells is linearly related to the activity of cell mitochondria. MTT tetrazolium dye is revived in active (metabolically) cells. Mitochondrial dehydrogenases in living cells produce NADH and $\mathrm{NADPH}$, leading to an insoluble purple precipitate called formazan. This precipitate can be dissolved by isopropanol or dimethyl sulfoxide [28]. Dead cells, on the other hand, are unable to perform this conversion due to the inactivity of their mitochondria and therefore do not show a signal. In this method, dye formation is used as a marker for the presence of living cells [29]. In recent years, MTT testing has been the most important measurement method to evaluate the toxicity and anti-cancer effects of molecules [30].

In the recent study, the cells treated with different concentrations of hydroxysafflor yellow A were assessed by MTT assay for $48 \mathrm{~h}$ as regards the cytotoxic properties towards SBC-3, DMS273, and DMS114 cell lines. The absorbance rate was evaluated at $570 \mathrm{~nm}$, which represented viability on the normal cell line (HUVEC) even up to $1000 \mu \mathrm{g} / \mathrm{ml}$ for hydroxysafflor yellow A (Table I, Figures 1, 2).

The viability of small cell lung cancer cell lines decreased dose-dependently in the presence of 
Table I. IC of hydroxysafflor yellow $A$ in the antismall cell lung cancer test

\begin{tabular}{|lc|}
\hline Variable & Hydroxysafflor yellow $A[\mu \mathrm{g} / \mathrm{ml}]$ \\
\hline$I C_{50}$ against HUVEC & - \\
\hline$I C_{50}$ against SBC-3 & $539 \pm 0$ \\
\hline$I C_{50}$ against DMS273 & $432 \pm 0$ \\
\hline$I C_{50}$ against DMS114 & $416 \pm 0$ \\
\hline
\end{tabular}

hydroxysafflor yellow $A$. The $I C_{50}$ values of hydroxysafflor yellow A were 539, 432, and $416 \mu \mathrm{g} / \mathrm{ml}$ against SBC-3, DMS273, and DMS114 cell lines, respectively (Table I; Figures 1, 2). The best result was achieved in the case of the DMS114 cell line. It appears that the anti-human small cell lung cancer effect of the studied molecule is due to its antioxidant effects. Because tumor progression is so closely linked to inflammation and oxidative stress, a compound with anti-inflammatory or antioxidant properties can be an anticarcinogenic agent [31].

Many molecules have pharmacological and biochemical properties, including antioxidant and anti-inflammatory properties, which appear to be involved in anticarcinogenic and antimutagenic activities. Today, molecules synthesized by biological methods play a vital role in treating many diseases, including cancer [32]. Molecules synthesized by biological methods are no longer the only ones in traditional medicine; in addition, they

A

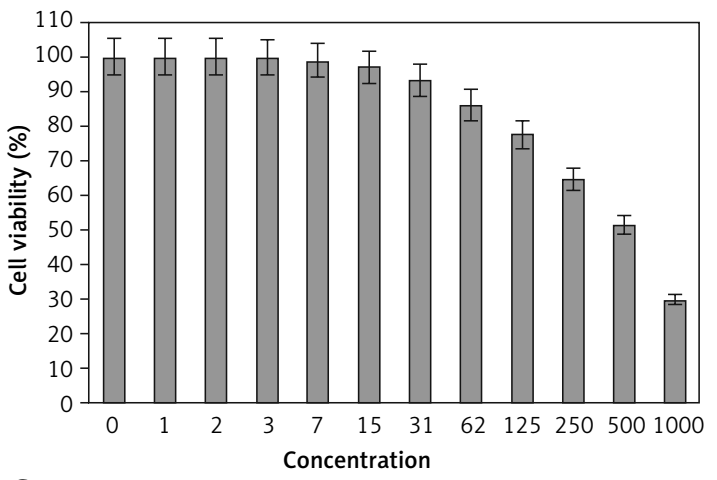

C

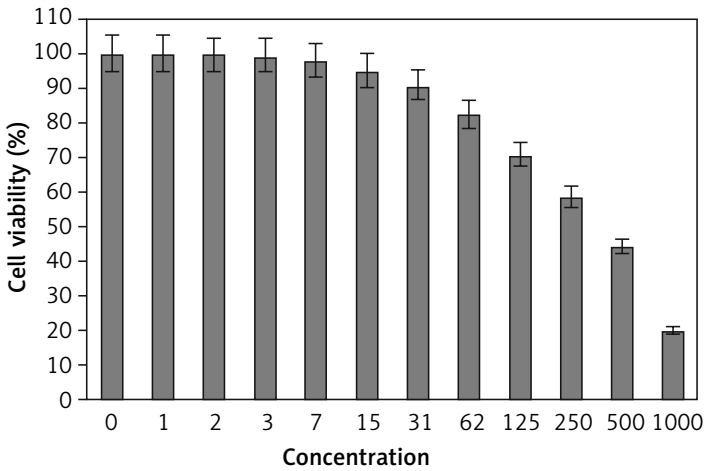

have been able to adopt an industrial line of natural products for treating various cancers. Various cell lines from cancers of the prostate, ovary, lung, liver, and pancreas have been treated with synthesized herbal molecules [31, 32].

\section{Enzyme results}

During the experiments, N-(3-[2-furyl]acryloyl)Leu-Gly-Pro-Ala (FALGPA) (Sigma F5135) as a collagenase substrate and collagenase (Sigma) C0130 Collagenase Clostridium histolyticum $2 \mathrm{U} / \mathrm{ml}$ ) were used. It was observed that the chemical substance we used in our study inhibits the collagenase enzyme. It can be suggested that the chemical substance, which has a high level of collagenase inhibitory effect, may be suitable for use as a collagenase inhibitor in addition to drug therapy in skin and dental diseases [33]. However, further studies are needed to prove the collagenase enzyme inhibition of this chemical substance through in vivo experiments. In our study, hydroxysafflor yellow A was found to inhibit the collagen enzyme at a high rate. This compound is an antioxidant substance and contains a hydroxy group in its structure [34]. It can be suggested that the hydroxy group in the catechin may have an effect on the collagenase enzyme, as is the case with other hydroxy group containing compounds [35]. In the hydroxysafflor yellow A we used in our study, the inhibitory effects on the collagenase enzyme have an $\mathrm{IC}_{50}$ value at the micromolar level.

B

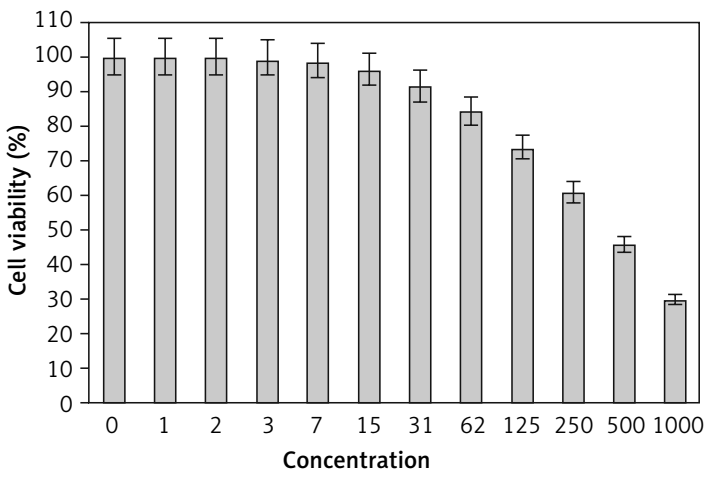

Figure 1. Anti-small cell lung cancer properties of hydroxysafflor yellow A against SBC-3 (A), DMS273 (B), and DMS114 (C) cell lines 
Hydroxysafflor yellow A is a flavonoid substance. It is reported that this substance prevents much damage in the body. In the trials of collagenase enzyme inhibition by Galardy and Grobelny [36] with phosphoric and phosphonic amides containing glycine, proline, leucine, phenyl and alanine, it was found that phosphoric amides containing glycine, proline and alanine inhibited this enzyme with an inhibition value of $\mathrm{IC}_{50}=14 \pm 6 \mu \mathrm{M}$. In our study, the inhibitory effect of hydroxysafflor yellow A on collagenase showed a lower value, $\mathrm{IC}_{50}=78.81 \mu \mathrm{g} / \mathrm{ml}$. Based on all this information, the inhibitory effects of various plant extracts, various chemicals, acids, vitamins, amino acids and peptides on this enzyme were investigated, considering the role of collagenase enzyme in skin aging and wound healing [37, 38].

\section{Molecular modeling results}

The biological and chemical activities of hydroxysafflor yellow A were assessed utilizing the molecular docking study. Figure 3 shows hydroxysafflor yellow A in the docking pose, and Figure 4 indicates the interactions of the hydroxysafflor yellow A with collagenase. As can be seen, the molecule has created some hydrogen bonds with Lys353, Asp398, Arg464, Tyr465, and Lys641. As can be clearly seen, the residue Lys353 has created two hydrogen bonds with the ligand. This residue and Asp398, Arg464, and Tyr465 are the residues of the catalytic subdomain, and Lys641 comes from the helper subdomain. 6 of 10 residues with hydrophobic contacts are also from the catalytic subdomain. Table II presents the parameters determined through the calculations. The docking

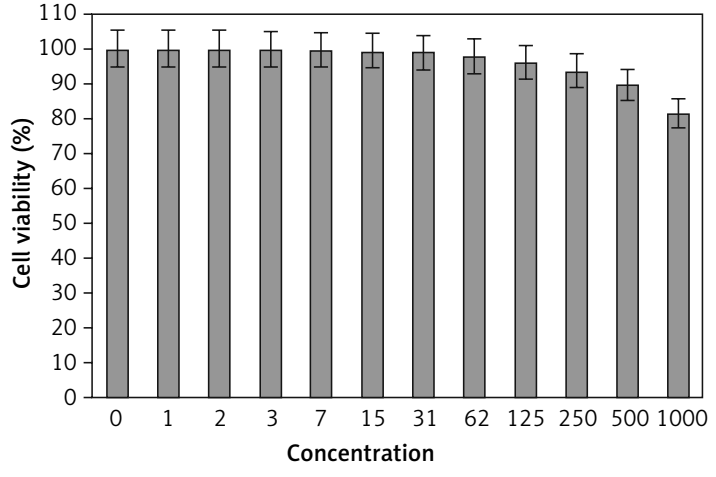

Figure 2. Cytotoxic effects of hydroxysafflor yellow $A$ against normal (HUVEC) cell line

score, as the most important calculated parameter [39], indicates the binding affinity between the ligands and enzyme. Another essential parameter is the Glide ligand efficiency, which shows the efficiency of the molecules numerically. Some other parameters such as Glide Evdw and Glide Ecoul are the parameters that are related to the interactions. The Glide energy is the energy of interaction that is numerically calculated, and the value of the interaction pose is calculated and presented with Glide Emodel [40]. These results indicated that hydroxysafflor yellow A could be considered as a potential inhibitor of collagenase. Generally, this inhibitor creates various interactions such as hydrogen bonds and hydrophobic contacts with the catalytic subdomain of the enzyme.

In conclusion, based on these results, we suggest hydroxysafflor yellow $A$ as a promising source for new anti-collagenase agents. In view of the importance that the maintenance of collagen structure has in preventing skin ageing and pho-

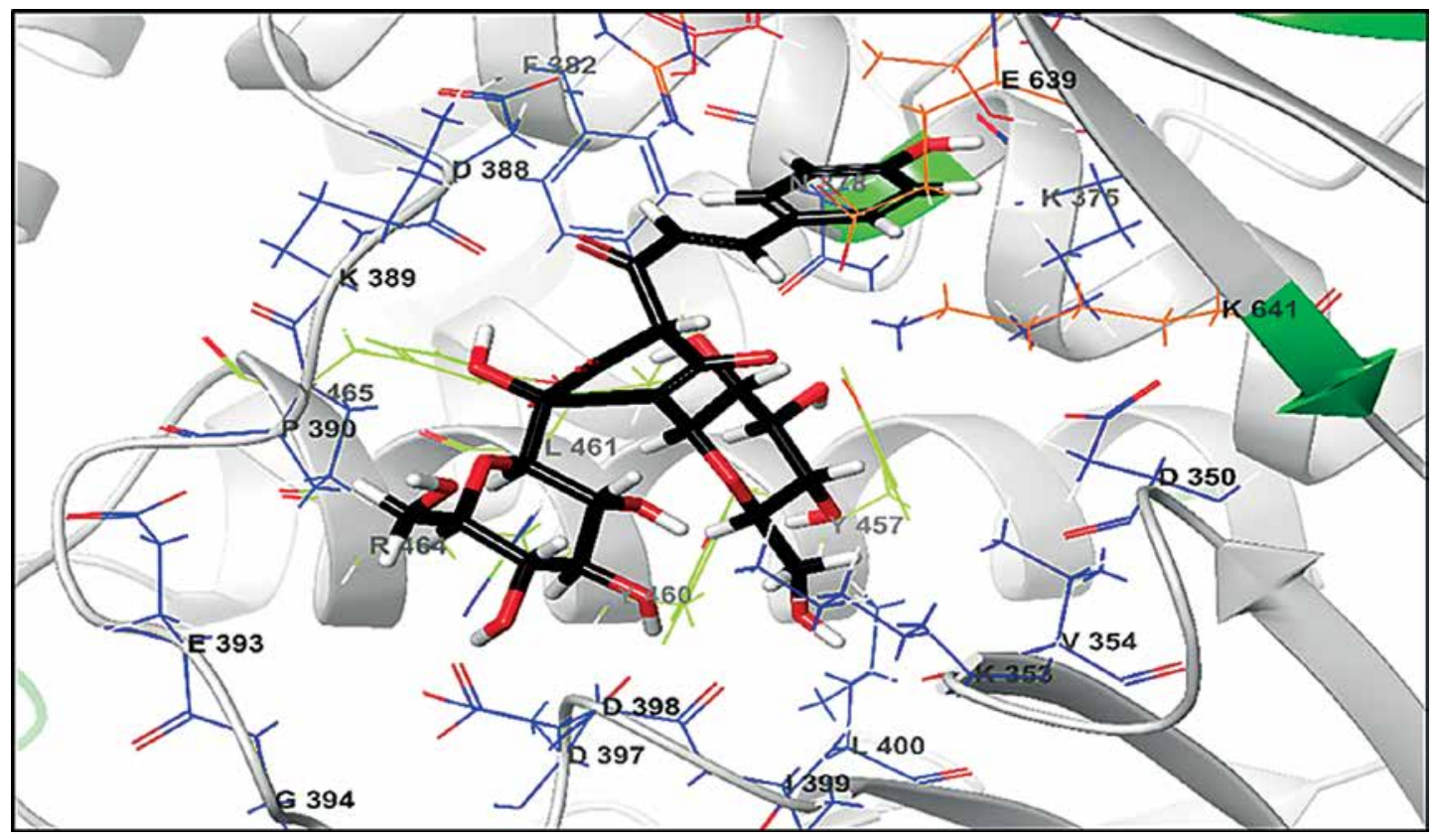

Figure 3. Docking pose of hydroxysafflor yellow A among the residues of collagenase 


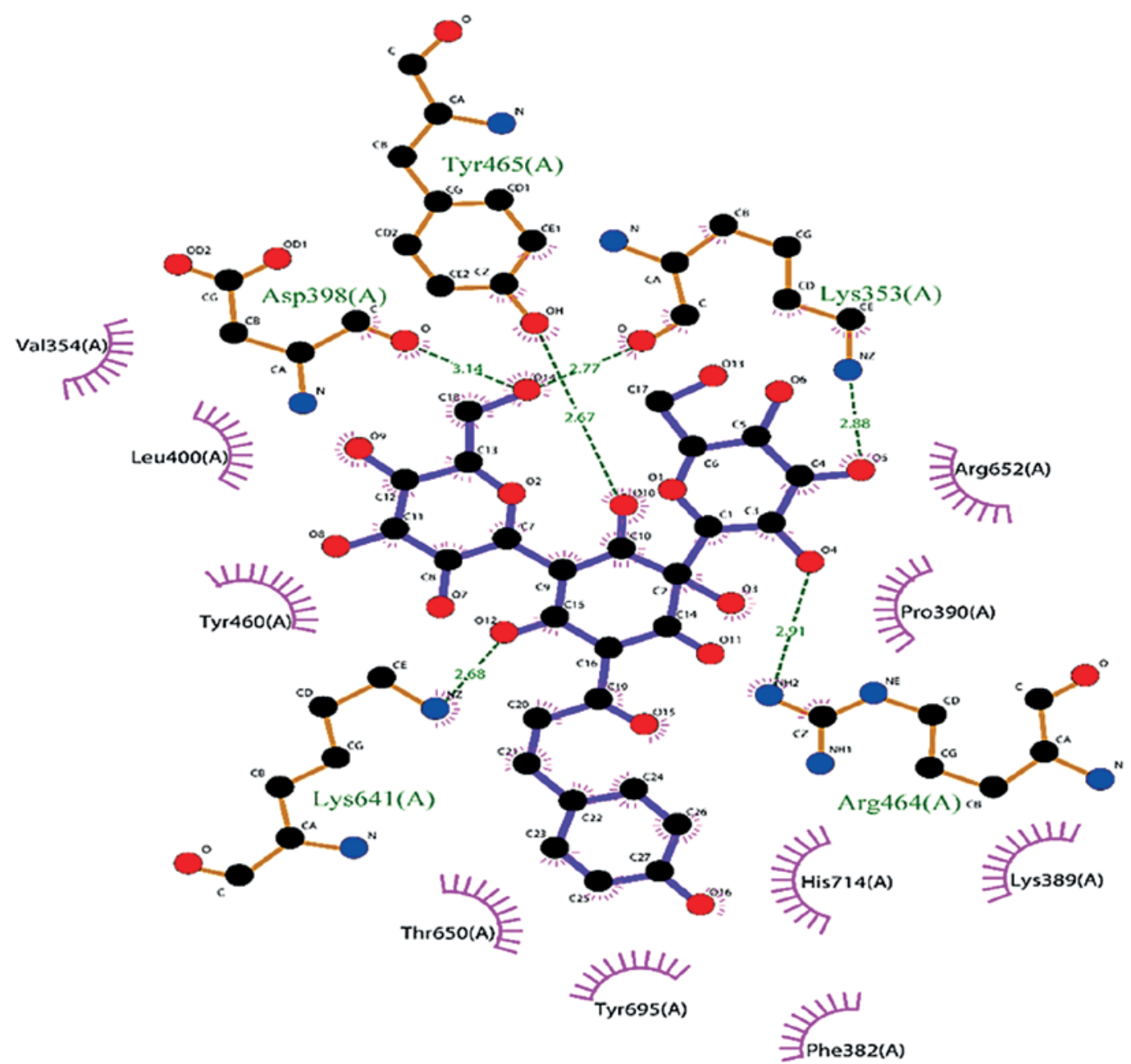

Figure 4. Interactions of hydroxysafflor yellow A and collagenase. Green dashed lines indicate the hydrogen bonds, and semicircles show the hydrophobic contacts

Table II. Parameters obtained from the molecular docking calculations

\begin{tabular}{|lc|}
\hline Parameter & $\begin{array}{c}\text { Hydroxysafflor } \\
\text { yellow A }\end{array}$ \\
\hline $\mathrm{IC}_{50}[\mathrm{mM}]$ & 78.81 \\
\hline Docking score $[\mathrm{kcal} / \mathrm{mol}]$ & -9.238 \\
\hline Glide ligand efficiency $[\mathrm{kcal} / \mathrm{mol}]$ & -0.215 \\
\hline Glide Ecoul $[\mathrm{kcal} / \mathrm{mol}]$ & -18.820 \\
\hline Glide Evdw $[\mathrm{kcal} / \mathrm{mol}]$ & -30.047 \\
\hline Glide Emodel $[\mathrm{kcal} / \mathrm{mol}]$ & -70.443 \\
\hline Glide energy $[\mathrm{kcal} / \mathrm{mol}]$ & -48.867 \\
\hline
\end{tabular}

toageing processes, this molecule can be included in active ingredients in wrinkle-care cosmetics. The viability of small cell lung cancer cell lines decreased dose-dependently in the presence of hydroxysafflor yellow $A$. The $I C_{50}$ values of hydroxysafflor yellow A were 539, 432, and $416 \mu \mathrm{g} / \mathrm{ml}$ against SBC-3, DMS273, and DMS114 cell lines, respectively. The results of experimental studies could be further assessed by the theoretical approaches to provide adequate insight into the mechanisms. Molecular docking studies are among the approaches that can reveal the biological activities of compounds in the presence of enzymes. In this study, the activities of hydroxysafflor yellow A against collagenase were evaluated using docking calculations. It was concluded that this compound has a considerable binding affinity to the enzyme by creating suitable bonds and interactions.

\section{Acknowledgments}

We acknowledge Taif University for Researchers Supporting Project (TURSP - number 2020/83), Taif University, Taif, Saudi Arabia.

\section{Conflict of interest}

The authors declare no conflict of interest. 


\section{References}

1. Zhang Y, Guo J, Dong H, et al. Niu Hydroxysafflor yellow A protects against chronic carbon tetrachloride-induced liver fibrosis. Eur J Pharmacol 2011; 660: 438-44.

2. Zhang L, Nie PH, Zhang GH, Rong WF, Zhi JM. Endothelium-independent vasodilation effect of hydroxysafflor yellow A in thoracic aorta of Wistar rats. J Med Plants Res 2011; 5: 2187-91.

3. Wu W, Li JR, Piao YZ, Dong NN, Jin M. Inhibitory effect of hydroxysafflor yellow A against rat myocardial mitochondrial injury. Chin Pharm J 2006; 41: 1225-7.

4. Tian J, Li G, Liu Z, Fu F. Hydroxysafflor yellow A inhibits rat brain mitochondrial permeability transition pores by a free radical scavenging action. Pharmacology 2008; 82: 121-6.

5. Ji DB, Zhang LY, Li CL, Ye J, Zhu HB. Effect of Hydroxysafflor yellow $A$ on human umbilical vein endothelial cells under hypoxia. Vasc Pharmacol 2009; 50: 137-45.

6. Han B, Zhao H. Effects of hydroxysafflor yellow A in the attenuation of MPTP neurotoxicity in mice. Neurochem Res 2010; 35: 107-13.

7. Villegas MR, Baeza A, Usategui A, Ortiz-Romero PL, Pablos JL, Vallet-Regi M. Collagenase nanocapsules: an approach to fibrosis treatment. Acta Biomater 2018; 74: 430-8.

8. Villegas MR, Baeza A, Vallet-Regí M. Hybrid collagenase nanocapsules for enhanced nanocarrier penetration in tumoral tissues. ACS Appl Mater Interfaces 2015; 7: 24075-81.

9. Vaccaro S, Caputo M, Cuppari C, Gennari G; Fidia Farmaceuticals SpA. New process for the production and purification of the collagenase enzyme from vibrio alginolyticus. US Pat 2017; 9: 738-883.

10. Tanaka K, Teramura N, Hayashida O, lijima K, Okitsu T, Hattori S. The C-terminal segment of collagenase in Grimontia hollisae binds collagen to enhance collagenolysis. FEBS Open Bio 2018; 8: 1691-702.

11. Alipour H, Raz A, Zakeri S, Djadid ND. Therapeutic applications of collagenase (metalloproteases): a review. Asian Pac J Trop Biomed 2016; 6: 975-81.

12. Mittal S, Malde A, Selvam C, et al. Synthesis and evaluation of S-4-(3-thienyl)phenyl-alpha-methylacetic acid. Bioorg Med Chem Lett 2004; 14: 979-82.

13. Jhong CH, Riyaphan J, Lin SH, Chia YC, Weng CF. Screening alpha-glucosidase and alpha-amylase inhibitors from natural compounds by molecular docking in silico. BioFactors 2015; 41: 242-51.

14. Arunachalam KD, Annamalai SK, Hari S. One-step green synthesis and characterization of leaf extract-mediated biocompatible silver and gold nanoparticles from Memecylon umbellatum. Int J Nanomed 2003; 8: 1307-15.

15. Thring TS, Hili P, Naughton DP. Anti-collagenase, an ti-elastase and anti-oxidant activities of extracts from 21 plants. BMC Complement Altern Med 2009; 9: 27.

16. Barrantes E, Guinea M. Inhibition of collagenase and metalloproteinases by aloins and aloe gel. Life Sci 2003; 72: 843-50

17. Van Wart HE, Steinbrink DR. A continuous spectrophotometric assay for Clostridium histolyticum collagenase. Anal Biochem 1981; 113: 356-65.

18. Wittenauer J, Mäckle S, Sußmann D, SchweiggertWeisz U, Carle R. Inhibitory effects of polyphenols from grape pomace extract on collagenase and elastase activity. Fitoterapia 2015; 101: 179-87.

19. Chatatikun M, Chiabchalard A. Thai plants with high antioxidant levels, free radical scavenging activity, anti-tyrosinase and anti-collagenase activity. BMC Complement Altern Med 2017; 17: 487.
20. Eckhard U, Schönauer E, Brandstetter H. Structural basis for activity regulation and substrate preference of clostridial collagenases G, H, and T. J Biol Chem 2013; 288: 20184-94.

21. Schrödinger Release 2020-4: Protein Preparation Wizard; Epik, Schrödinger, LLC, New York, NY 2016; Impact, Schrödinger, LLC, New York, NY 2016; Prime, Schrödinger, LLC, New York, NY 2020.

22. Chakraborti AK, Thilagavathi R. Computer-aided design of non sulphonyl COX-2 inhibitors: an improved comparative molecular field analysis incorporating additional descriptors and comparative molecular similarity indices analysis of 1,3-diarylisoindole derivatives. Bioorg Med Chem 2003; 11: 3989-96.

23. Schrödinger Release 2020-4: LigPrep, Schrödinger, LLC, New York, NY 2020.

24. Arunachalam KD, Annamalai SK, Hari S. One-step green synthesis and characterization of leaf extract-mediated biocompatible silver and gold nanoparticles from Memecylon umbellatum. Int J Nanomed 2003; 8: 1307-15.

25. Veisi H, Tamoradi T, Karmakar B, Mohammadi P, Hemmati S. In situ biogenic synthesis of Pd nanoparticles over reduced graphene oxide by using a plant extract (Thymbra spicata) and its catalytic evaluation towards cyanation of aryl halides. Mater Sci Eng C Mater Biol Appl 2019; 104: 109919.

26. You C, Han C, Wang X, et al. The progress of silver nanoparticles in the antibacterial mechanism, clinical application and cytotoxicity. Mol Biol Rep 2012; 39: 9193-201.

27. Mao BH, Tsai JC, Chen CW, et al. Mechanisms of silver nanoparticle-induced toxicity and important role of autophagy. Nanotoxicology 2016; 10: 1021-40.

28. Namvar F, Rahman HS, Mohamad R, et al. Cytotoxic effect of magnetic iron oxide nanoparticles synthesized via seaweed aqueous extract. Int J Nanomedicine 2014; 19: 2479-88.

29. Sankar R, Maheswari R, Karthik S, et al. Anticancer activity of Ficus religiosa engineered copper oxide nanoparticles. Mat Sci Eng C 2014; 44: 234-9.

30. Katata-Seru L, Moremedi T, Aremu OS, et al. Green synthesis of iron nanoparticles using Moringa oleifera extracts and their applications: Removal of nitrate from water and antibacterial activity against Escherichia coli. J Mol Liq 2018; 256: 296-304.

31. Beheshtkhoo N, Kouhbanani MAJ, Savardashtaki A, et al. Green synthesis of iron oxide nanoparticles by aqueous leaf extract of Daphne mezereum as a novel dye removing material. Appl Phys A 2018; 124: 363-9.

32. Sangami S, Manu M. Synthesis of Green Iron Nanoparticles using Laterite and their application as a Fenton-like catalyst for the degradation of herbicide Ametryn in water. Environ Technol Innov 2017; 8: 150-63.

33. Barrantes E, Guinea M. Inhibition of collagenase and metalloproteinases by aloins and aloe gel. Life Sci 2003; 72: 843-50.

34. Van Wart HE, Steinbrink DR. A continuous spectrophotometric assay for Clostridium histolyticum collagenase. Anal Biochem 1981; 113: 356-65.

35. Demina NS, Lysenko SV. Collagenolytic enzymes synthesized by microorganisms. Mikrobiologiia 1996; 65: 293-304.

36. Obayashi K, Akamatsu H, Okano Y, Matsunaga K, Masa$\mathrm{ki} \mathrm{H}$. Exogenous nitric oxide enhances the synthesis of type I collagen and heat shock protein 47 by normal human dermal fibroblasts. J Dermatol Sci 2006; 41: 121-6.

37. Abdul Wahab N, Abdul Rahman R, Ismail A, Mustafa S, Hashim P. Assessment of antioxidant capacity, anti-col- 
lagenase and antielastase assays of Malaysian unfermented cocoa bean for cosmetic application. Nat Prod Chem Res 2014; 2: 3.

38. Thring TS, Hili P, Naughton DP. Anti-collagenase, antielastase and anti-oxidant activities of extracts from 21 plants. BMC Complement Altern Med 2009; 9: 27.

39. Subhani S, Jayaraman A, Jamil K. Homology modelling and molecular docking of MDR1 with chemotherapeutic agents in non-small cell lung cancer. Biomed Pharmacother 2015; 71: 37-45.

40. Türe A, Kahraman DC, Cetin-Atalay R, Helvacıoglu S, Charehsaz M, Küçükgüzel i. Synthesis, anticancer activity, toxicity evaluation and molecular docking studies of novel phenylaminopyrimidine - (thio)urea hybrids as potential kinase inhibitors. Comput Biol Chem 2019; 78: 227-41. 